\title{
Novel strategy for pedunculated colon polyps after unsuccessful conventional therapy
}

\author{
Shintaro Fujihara MD PhD, Hideki Kobara MD PhD, Hirohito Mori MD PhD, Noriko Nishiyama MD, \\ Yasuhiro Goda MD, Tsutomu Masaki MD PhD
}

\begin{abstract}
T o prevent postpolypectomy bleeding, proper placement of the endoloop and prophylactic clips are important $(1,2)$. However, in cases of giant pedunculated polyps with wide stalks, endoloop placement requires proficiency, especially in the narrow lumen and against large polyp heads. Furthermore, prophylactic clips often do not effectively occlude the blood supply to these polyps, which makes them unsuitable for resection. In the present report, a strategy for this type of polyp using grasping-type scissors forceps is described. To the authors' knowledge, the present report is the first to describe using graspingtype scissors forceps to resect a giant pedunculated polyp.
\end{abstract}

\section{CASE PRESENTATION}

A 79-year-old man with occult bleeding was admitted to the authors' hospital. At screening colonoscopy, a pedunculated polyp $35 \mathrm{~mm}$ in size was observed at the sigmoid colon (Figure 1). Conventional therapy was attempted as a first choice; however, capturing the wide stalk by encircling its large head was difficult. Moreover, the blood supply

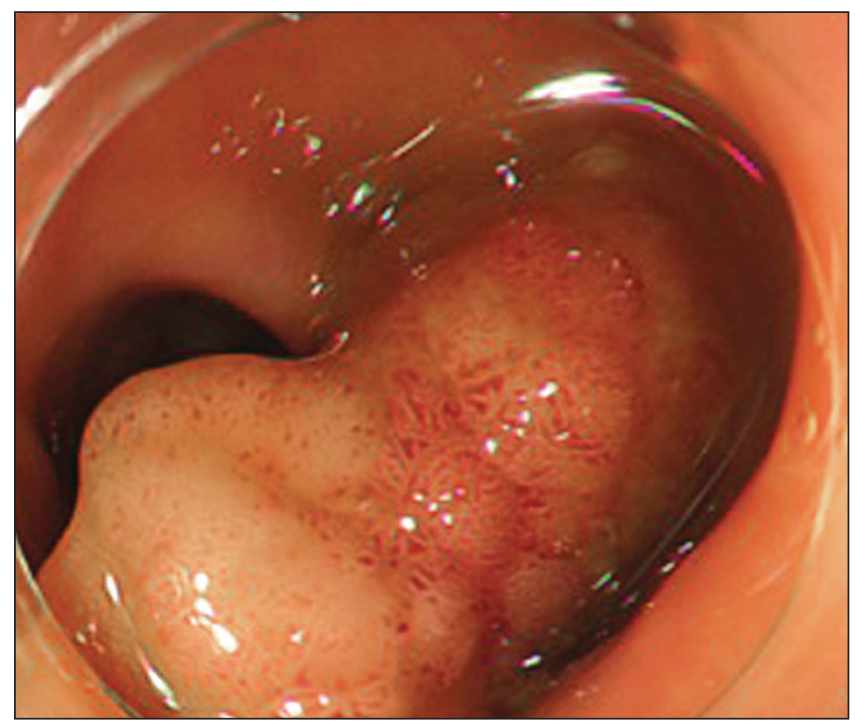

Figure 1) A large pedunculated polyp with a $35 \mathrm{~mm}$ head and a wide stalk in the sigmoid colon was not effectively blocked by application of prophylactic clips to both sides of the stalk. Therefore, the use of grasping-type scissors forceps (Clutch Cutter, Fujifilm, Japan) was proposed. After cutting the mucosa of the stalk with a dual electrosurgical knife (KD-650 Q: Olympus, Japan) with electrosurgical generator (VIO300D; ERBE Co, Germany), the forceps resection of the stalk (swift coagulation, effect 4 , $60 \mathrm{~W}$ ) (Figure 2) and hemostasis of its large blood vessels (soft coagulation, effect $5,60 \mathrm{~W}$ ) was peformed. This manoeuvre took approximately $30 \mathrm{~min}$, and prophylactic clips were applied to the base of the stalk. Histopathology examination revealed a tubular adenocarcinoma and curative resection.

The described manoeuvres suggest that grasping-type scissors forceps can facilitate manipulations such as rotation, grasping, incision and resection without specialized technical skills $(3,4)$ (Figure 3). Additionally, they are capable of controlling bleeding by soft coagulation. Therefore, this device can be effective for safe resection of giant pedunculated polyps.

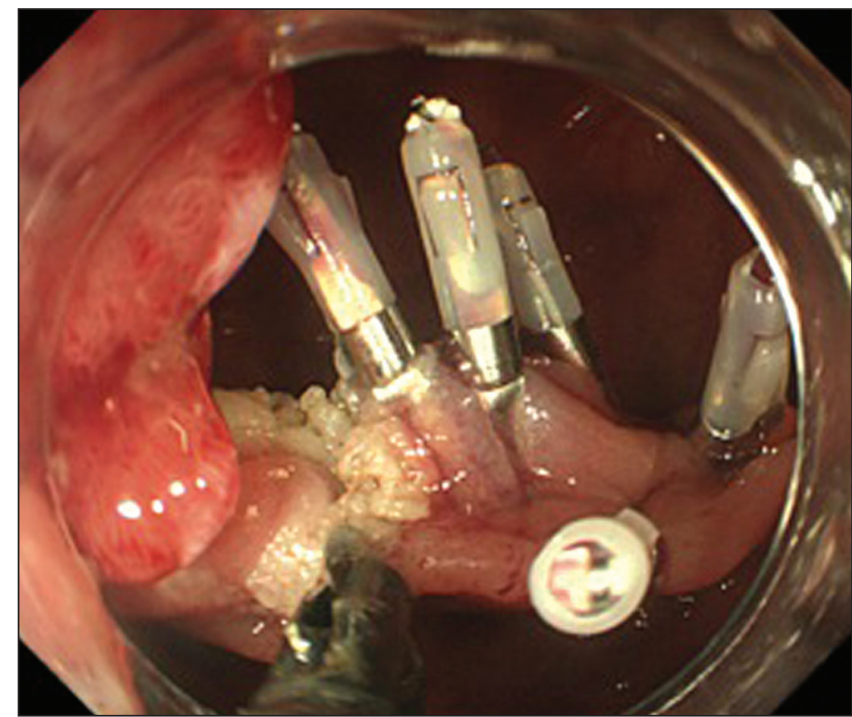

Figure 2) Endoscopic view of the resection using grasping-type scissors forceps after clamping of the stalk. A strong blood supply to the vessels was observed, and these vessels were coagulated using a grasping-type scissors forceps

Departments of Gastroenterology and Neurology, Faculty of Medicine, Kagawa University, Takamatsu, Japan

Correspondence: Dr Shintaro Fujihara, Department of Gastroenterology and Neurology, Kagawa University Faculty of Medicine / Graduate School of

Medicine, 1750-1 Ikenobe, Miki-cho, Kita-gun, Kagawa Prefecture, 761-0793 Japan. Telephone 81-87-891-2156, fax 81-87-891-2158,

e-mail sannai@kms.ac.jp

Received for publication March 18, 2015. Accepted March 23, 2015 


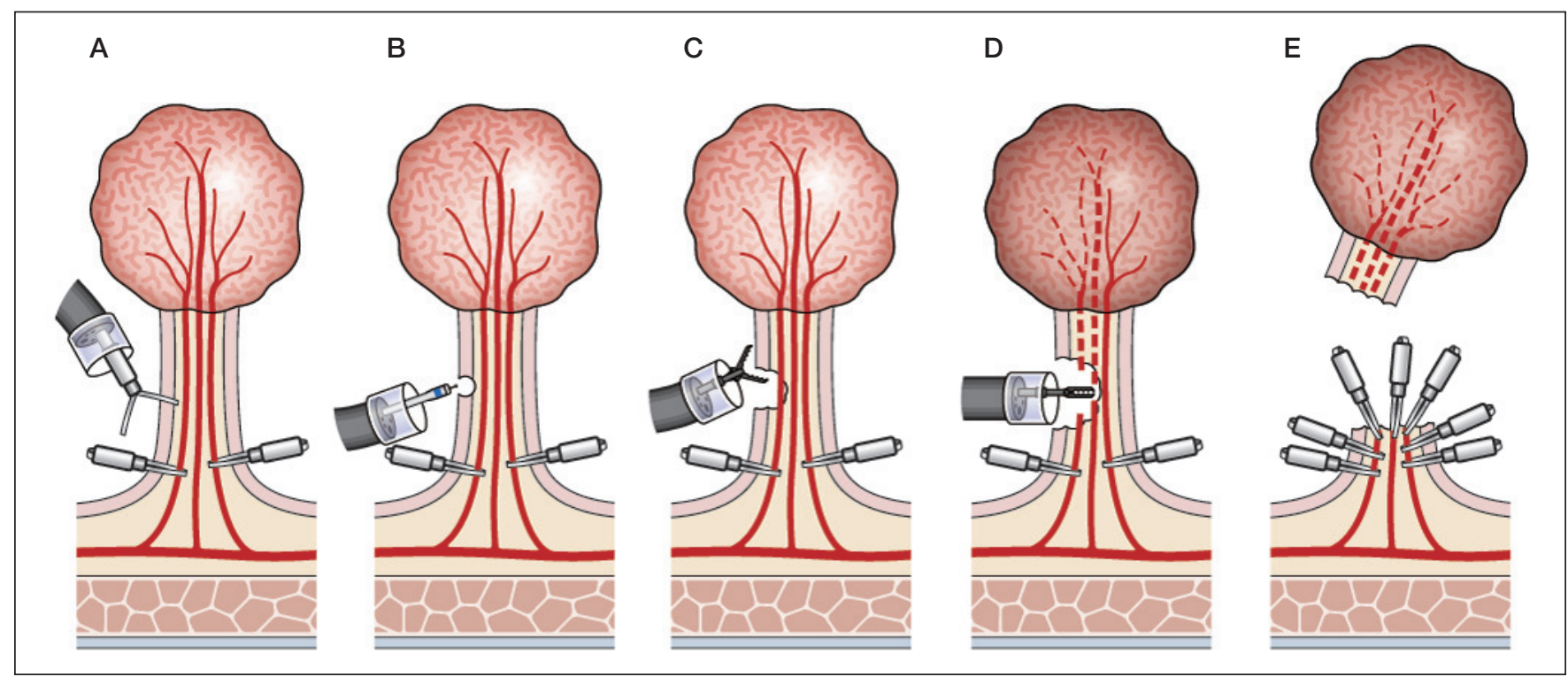

Figure 3) Schematic of endoscopic resection for a giant pedunculated polyp with grasping-type scissor forceps. A Applying propylactic clips at the both sides of the stalk is ineffective in occluding the blood supply. B After injection of hyaluronic acid solution, which includes epinephrine and indigo carmine dye, to the stalk, a dual electrosurgical knife cuts mucosa of the stalk. C Grasping-type scissors forceps are then used to proceed with the resection. D Hemostasis is performed simultaneously, and bleeding is now controlled. E For better hemostasis, additional endoclips are applied around the stalk

DISCLOSURES: The authors have no financial disclosures or conflicts of interest to declare.

\section{REFERENCES}

1. Katsinelos P, Kountouras J, Paroutoglou G, et al. Endoloop-assisted polypectomy for large pedunculated colorectal polyps. Surg Endosc 2006;20:1257-61.

2. Ji J-S, Lee S-W, Kim T, et al. Comparison of prophylactic clip and endoloop application for the prevention of postpolypectomy bleeding in pedunculated colonic polyps: A prospective, randomized, multicenter study. Endoscopy 2014;46:598-604.
3. Akahoshi K, Honda K, Akahane $\mathrm{H}$ et al. Endoscopic submucosal dissection by using a grasping-type scissors forceps: a preliminary clinical study (with video). Gastroint Endosc 2008;67:1128-33.

4. Akahoshi K, Akahane H, Murata A, et al. Endoscopic submucosal dissection using a novel grasping type scissors forceps. Endoscopy 2007;39:1103-5.

The Canadian Journal of Gastroenterology Eु Hepatology is considering a limited number of submissions for IMAGE OF THE MONTH. These are based on endoscopic, histological, radiological and/or patient images, which must be anonymous with no identifying features visible. The patient must consent to publication and the consent must be submitted with the manuscript. All manuscripts should be practical and relevant to clinical practice, and not simply a case report of an esoteric condition. The text should be brief, structured as CASE PRESENTATION and DISCUSSION, and not more than 700 words in length. A maximum of three images can be submitted and the number of references should not exceed five. The submission may be edited by our editorial team. 


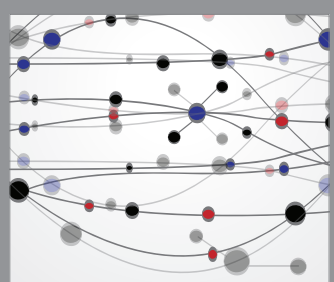

The Scientific World Journal
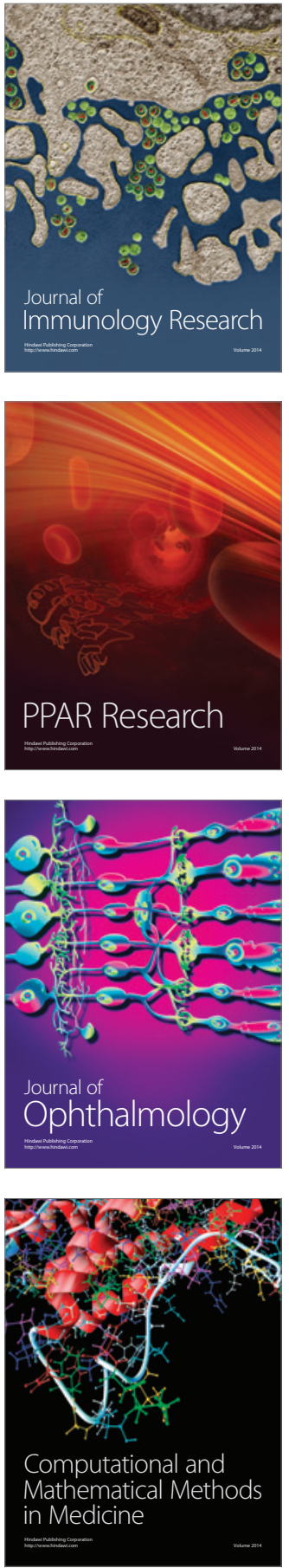

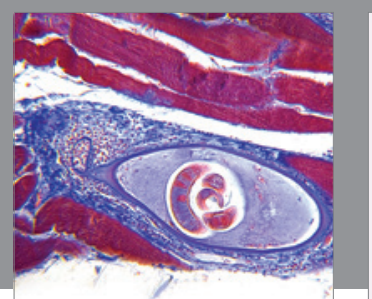

Gastroenterology Research and Practice

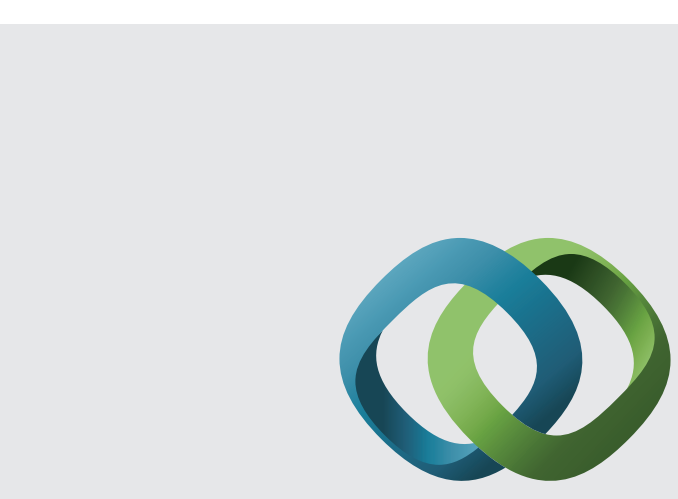

\section{Hindawi}

Submit your manuscripts at

http://www.hindawi.com
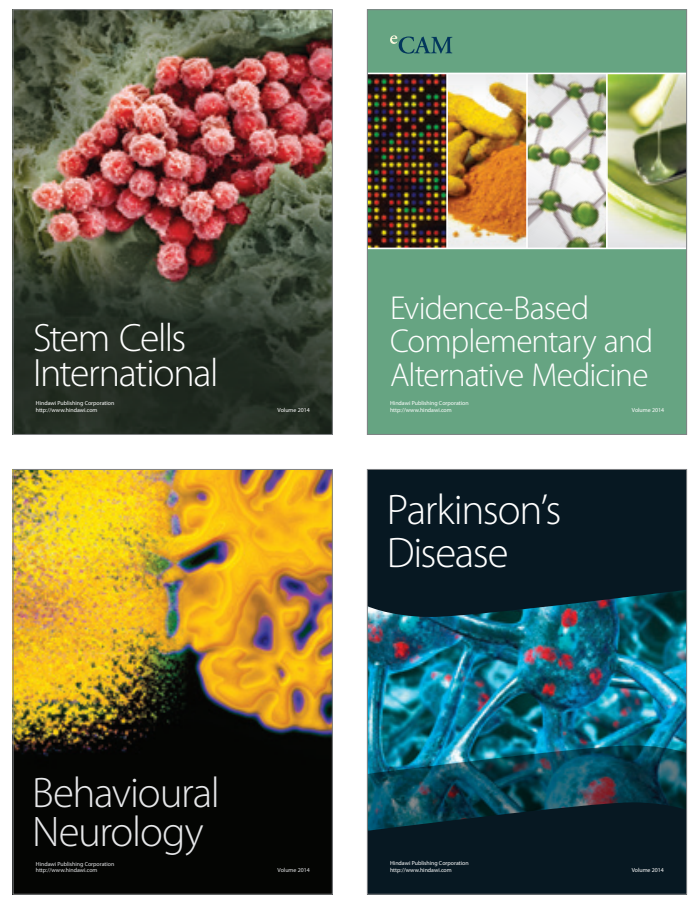
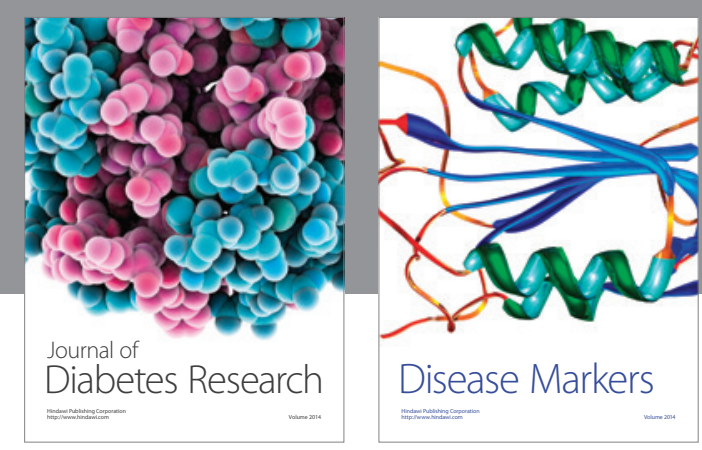

Disease Markers
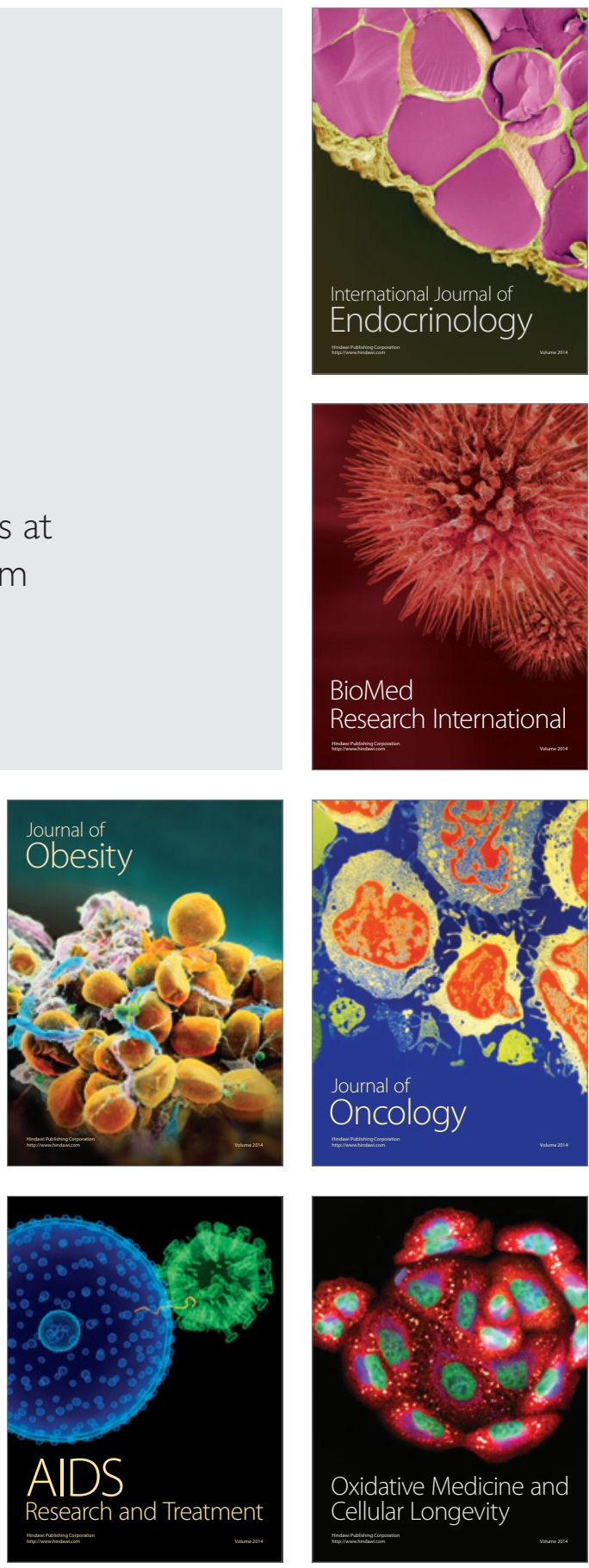